\title{
Komunikasi Bencana: \\ Aspek Sistem (Koordinasi, Informasi dan Kerjasama)
}

\author{
Setio Budi HH \\ Dosen Program Studi Ilmu Komunikasi \\ Universitas Atma Jaya Yogyakarta
}

\begin{abstract}
Abstrak
Berbagai peristiwa bencana di Indonesia memberikan pelajaran tentang pentingnya manajemen bencana. Secara kelembagaan BNPB merupakan institusi yang menjadi komando utama penanggulangan bencana. Pada kenyataannya berbagai problematika masih muncul dalam penanganan bencana, utamanya "KIKK", komunikasi, informasi, koordinasi dan kerjasama. Dalam manajemen bencana diperlukan pendekatan yang tepat yaitu pendekatan sistem, yang akan membantu dari proses mitigasi sampai pasca bencana dapat berjalan dengan baik, karena dilaksanakan secara terintergrasi dan sinergis antar lembaga dan komponen masyarakat
\end{abstract}

Kata Kunci : bencana, manajemen bencana, pendekatan sistem

\section{Abstract}

\begin{abstract}
Many catastrophic and disaster events in Indonesia provides a lesson on the importance of disaster management. Institutionally BNPB as main role and became the main command of disaster management. In reality many problems still arise in disaster management, especially "KIKK", communication, information, coordination and cooperation. In disaster management is needed right approach that is a systems approach, in which it helps the process from mitigation to post-disaster goes well, because implemented in integrated and synergistic in inter-agency and stakeholder.
\end{abstract} Keywords : disaster, disaster management, system approach of disaster
management

\section{Pengantar}

Bencana demi bencana, terutama dari faktor alam terus terjadi sampai saat ini. Terutama sejak peristiwa Tsunami Aceh tahun 2004 sampai hari ini, berbagai letusan gunung api, tanah longsor, banjir, gempa teknonik dan vulkanik, serta gas beracun, masih mengancam penduduk di seluruh Indonesia.

Badan Nasional Penanggulangan Bencana (BNPB) sebagai ujung tombak penanganan bencana nasional dan didukung oleh Badan Penanggulangan Bencana Daerah (BPMD) serta berbagai organisasi yang relevan seperti TNI, POLRI, BASARNAS, PMI, DEPSOS, dan berbagai perangkat pendukung seperti TAGANA, PRAMUKA, ORARI, RAPI, termasuk NGO, relawan berbagai organisasi telah memiliki pengalaman untuk melakukan mitigasi, penanganan sampai pasca bencana.

Walaupun demikian sampai saat ini 
berdasar pengamatan terhadap berbagai pemberitaan bencana di Indonesia, masih menunjukkan problematika di lapangan, sebagaimana yg dikemukakan Budi (2011 :23) bahwa setelah melalui berbagai penguatan landasan hukum , kelembagaan dan pengalaman penanganan bencana ternyata masih menyisakan banyak persoalan baik secara konseptual maupun lapangan. Persoalan utama adalah "KIKK", yaitu Komunikasi, Informasi, Koordinasi dan Kerjasama. Dari aspek kecepatan, ketepatan, keakuratan - keandalan, aspek komunikasi dan informasi menjadi hal yang masih problematik, terutama ketika berbicara mengenai kesimpangsiuran informasi, berbagai tindakan yang tidak tepat sasaran seperti logistik yang tidak merata, keterpaduan antar sektor dalam penanganan bencana atau ketumpang tindihan masih banyak terjadi. Pada satu sisi ini menunjukkan bahwa aspek egosentris sektoral masih nampak, pada sisi lain pemahaman atas aspek kebijakan dan implementasi yang terintegrasi mengenai aspek bencana belum menjadi agenda utama.

Problematika tersebut tentu harus diperbaiki, dan menjadi kesempatan untuk mengimplementasikan kebijakan, strategi dan operasional penanggulangan bencana sebagai suatu gerakan yang terintegrasi dan sistemik.

Miller and Rivera (2011 : 399) menunjukkan data bencana dari tahun 1900 - 2009 an, yang menunjukkan kecenderungan peningkatan peristiwa bencana, dan nampak diantaranya yang cukup dominan adalah banjir, badai, epidemic, gempa, tanah longsor, sebagaimana terlihat pada bagan dibawah ini :

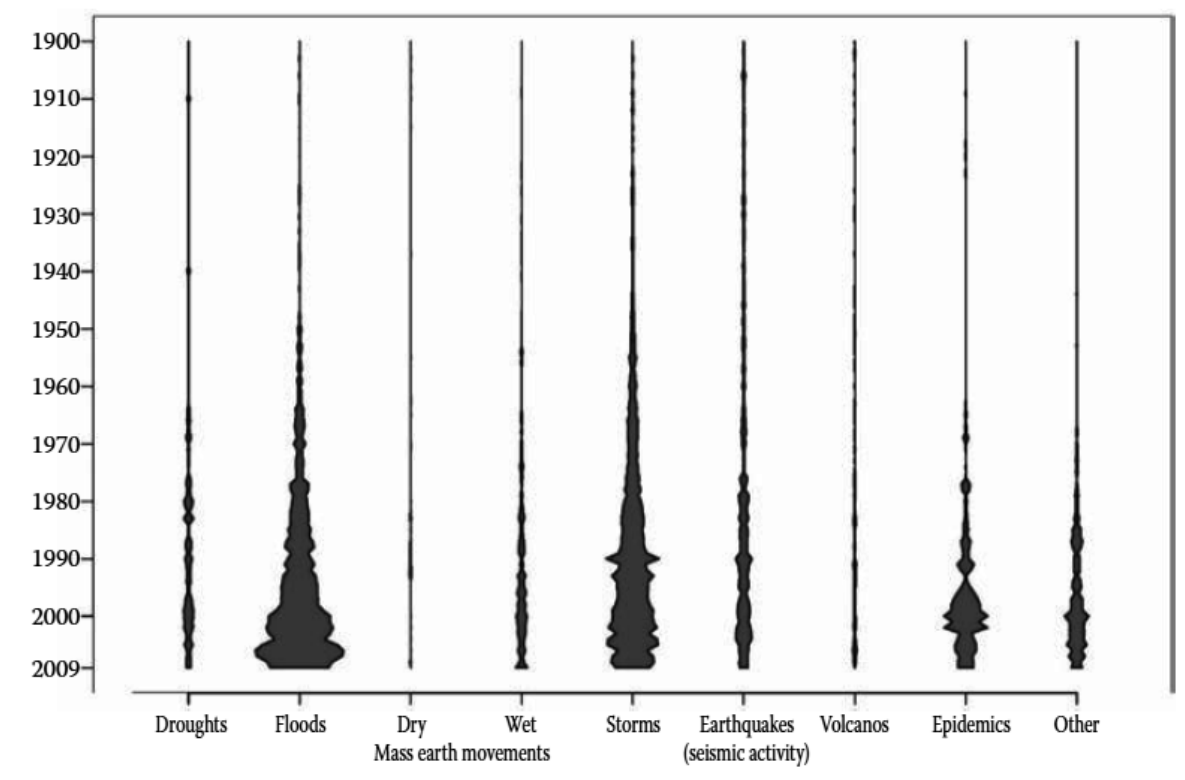

Bagan 1.a

Peningkatan Berbagai Peristiwa Bencana di Dunia Periode Tahun 1900 - 2009

Sumber Miller and Rivera (2011 : 399), mengutip International Disaster Database (http://www. emdat.be, Universite Chatolique de Louvain, Brussels, Belgium) 
Data diatas juga menunjukkan adanya potensi kecenderungan peningkatan potensi berbagai bencana yang terus meningkat. Apakah karena factor "global warming" atau karena implikasi dari eksploitasi manusia atas bumi, maka isu bencana yang "natural made dan man made" akan tetap menjadi perhatian.

Bandingkan dengan fenomena yang terjadi pada Indonesia, tahun 2010, sebagaimana bagan dibawah ini :

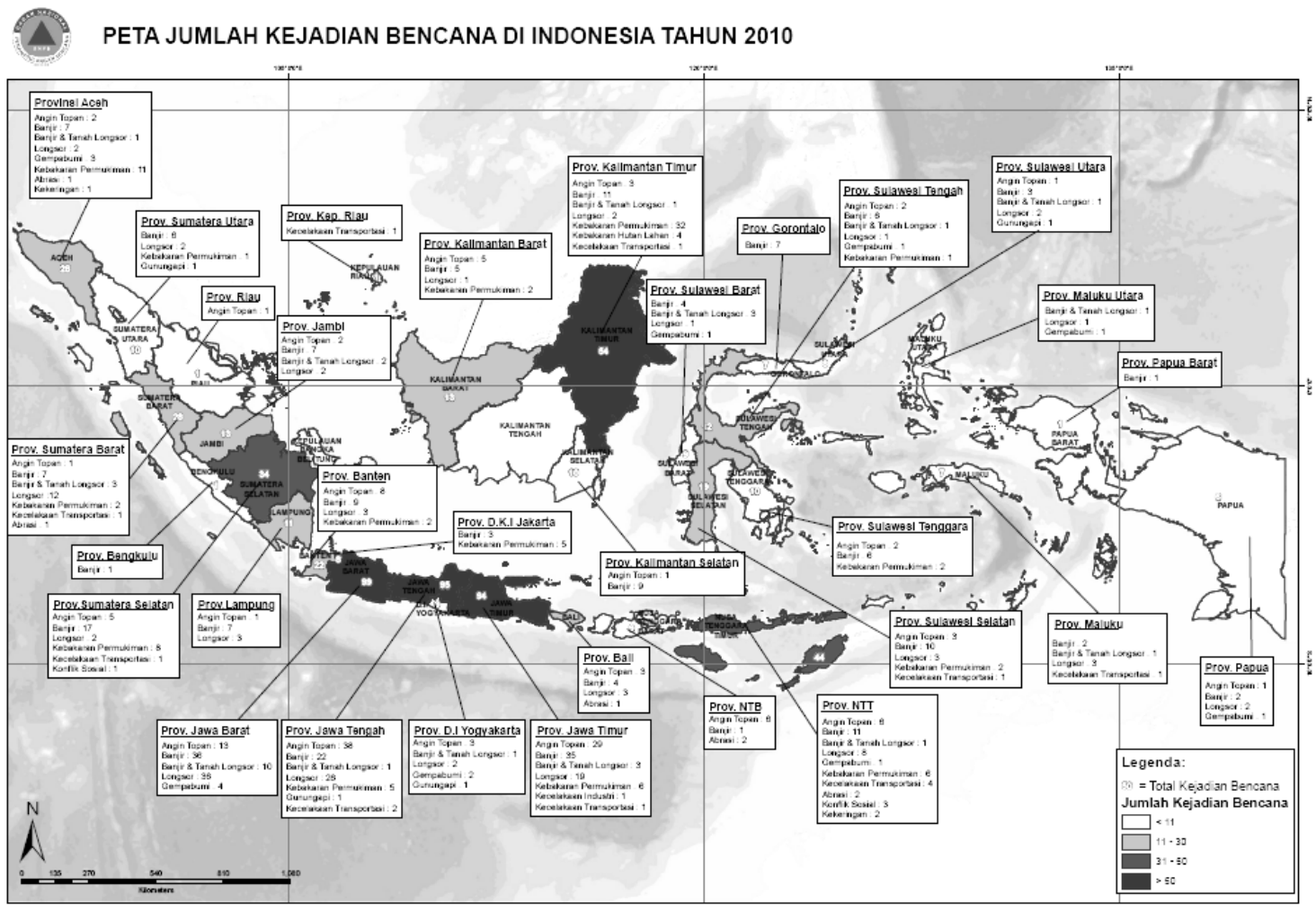

\section{Bagan 1.b \\ Peta Jumlah Kejadian Bencana Di Indonesia Tahun 2010}

Sumber : geospasial.bnpb.go.id

Dari data dapat dilihat, terdapat dua wilayah yang memiliki data jumlah kejadian bencana yang tinggi yaitu pulau Jawa dan Kalimantan Timur, dua dengan jumlah kejadian dibawahnya adalah NTT dan NTB serta Sumatera Selatan. Wilayah lain jumlahnya dibawah kedua wilayah tersebut diatas. Indikasi ini sebenarnya tetap menunjukkan bahwa Indonesia memiliki potensi bencana yang cukup besar, indikasinya adalah berbagai peristiwa yang terjadi terus menerus atau bergantian di tiap wilayah, atau juga kejadian yang berulang pada suatu wilayah yang sama, seperti kejadian banjir, gempa dan kebakarah hutan dan tanah longsor.

\section{Pendekatan Sistem Manajemen Bencana}

Coppola dan Maloney (2009 : 53-55) mengatakan bahwa manajemen bencana modern secara komprehensif mencakup empat komponen fungsional, yaitu : mitigation yang mencakup reduksi atau mengeliminasi komponen resiko bahaya. Kedua Preparedness, yang 
meliputi melengkapi masyarakat yang memiliki resiko terkena bencana atau menyiapkan agar mampu membantu orang pada peristiwa bencana dengan berbagai alat-alat/ perlengkapan untuk meningkatkan kemampuan bertahan dan meminimalisasikan resiko finansial serta resiko lainnya. Ketiga, Response mencakup tindakan yang dilakukan untuk mengurangi atau mengeliminasi dampak bencana, dan keempat Recovery, mencakup perbaikan, rekonstruksi atau mencapai kembali dari apa yang telah rusak/ hilang sebagai bagian dari bencana dan idealnyamengurangi resiko dari kekacauan yang sama dimasa depan.
Keempat komponen tersebut yang saat ini menjadi platform dalam melakukan penanganan bencana, menjadi dasar untuk melakukan dari operasional lapangan sampai ke pembuatan kebijakan dan strategi penanganan bencana. Simonovi'c (2011: 31), mengemukakan mengenai pendekatan sistem dalam manajemen bencana, bahwa manajemen bencana terintegrasi adalah proses pengambilan keputusan yang terus menerus yang mengacu pada pencegahan, respon dan pemulihan dari suatu peristiwa bencana. Secara ringkas digambarkan melalui bagan dibawah ini :

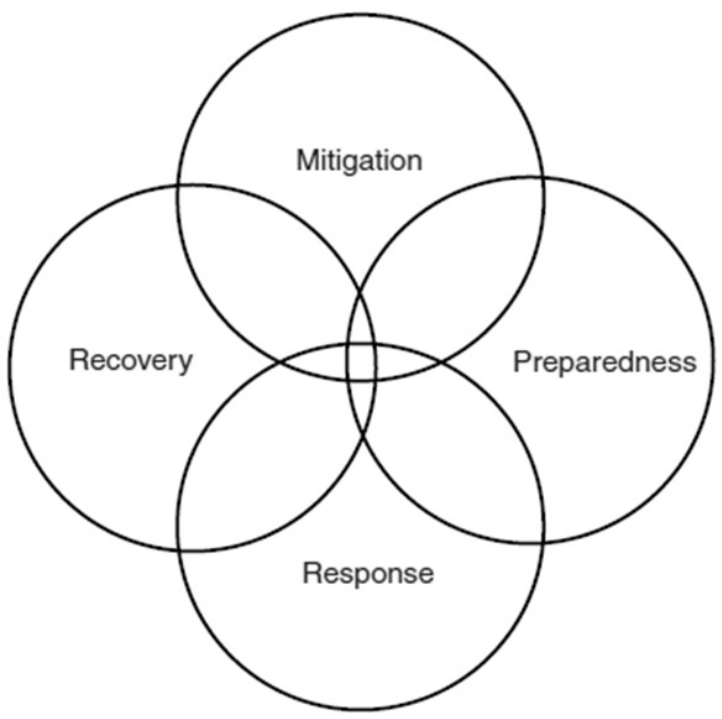

Bagan 2

The Venn diagram of integrated disaster management

Sumber : FEMA, http://training.fema.gov/emiweb/downloads/is10_unit3.doc (dalam Simonovi'c, $2011: 31$ )

Dalam penjelasan lebih lanjut dalam konsep pendekatan system tersebut, Simonovíc (2011: 38 - 41) mengemukakan tentang pentingnya mitigasi, yang merupakan perencanaan jangka panjang dan termasuk identifikasi aspek kerentanan dari bagian-bagian kewilayahan, mengacu khususnya pada ancaman - bahaya, dan mengidentifikasikan langkah-langkah yang harus diambil untuk meminimalkan resiko.

Tujuan dari kesiapsiagaan adalah untuk mengantisipasi problem-problem yang ada dalam suatu bencana, sehingga berbagai cara bisa dirancang 
untuk mengatasi problem tersebut secara efektif dan sumber-sumber daya yang dibutuhkan untuk melakukan respon yang efektif disiapkan sebelum (termasuk formulasi, tes, latihan, trainer, komunikasi publik). Selanjutnya aktivitas respon mencakup hunian darurat, SAR, penanganan korban, asesmen kerusakan dan pengukuran kedaruratan. Pada poin ini Simonovi'c mengemukakan bahwa petugas yang menangani pada tahap ini harus mengatasi berbagai kebutuhan seperti koordinasi, komunikasi, asesmen situasi terus menerus serta mobilisasi sumber daya yang diperlukan secara tepat. Pada tahap pemulihan menunjukkan suatu upaya terus menerus untuk melakukan rekonstruksi, restorasi, rehabilitasi dan pembangunan kembali pasca bencana.

Aspek-aspek mitigasi, kesiapsiagaan, respon dan pemulihan pasca bencana menjadi bagian-bagian yang sistemik dan terintegrasi dalam suatu kebijakan, strategi, manajemen dan operasional, dan tentu didukung oleh regulasi yang berskala nasional, regional dan lokal. Tidak bisa dibayangkan jika otonomi daerah kemudian meniadakan ruang untuk melakukan koordinasi dan operasi bencana bersama pada wilayah yang mencakup dua wilayah atau lebih.

Padasuatu peristiwabencana, operasi penanganan bencana akan melibatkan berbagai stakeholder yang masingmasing memiliki tugas, sumberdaya, ketrampilan, misi sampai kepentingan yang sama dan berbeda. Berbagai keluhan atau kritik atas fenomena suatu peristiwa bencana, merupakan pelajaran yang penting dalam manajemen bencana. Sebagaimana yang digambarkan oleh Budi (2011 : 33) dibawah ini :

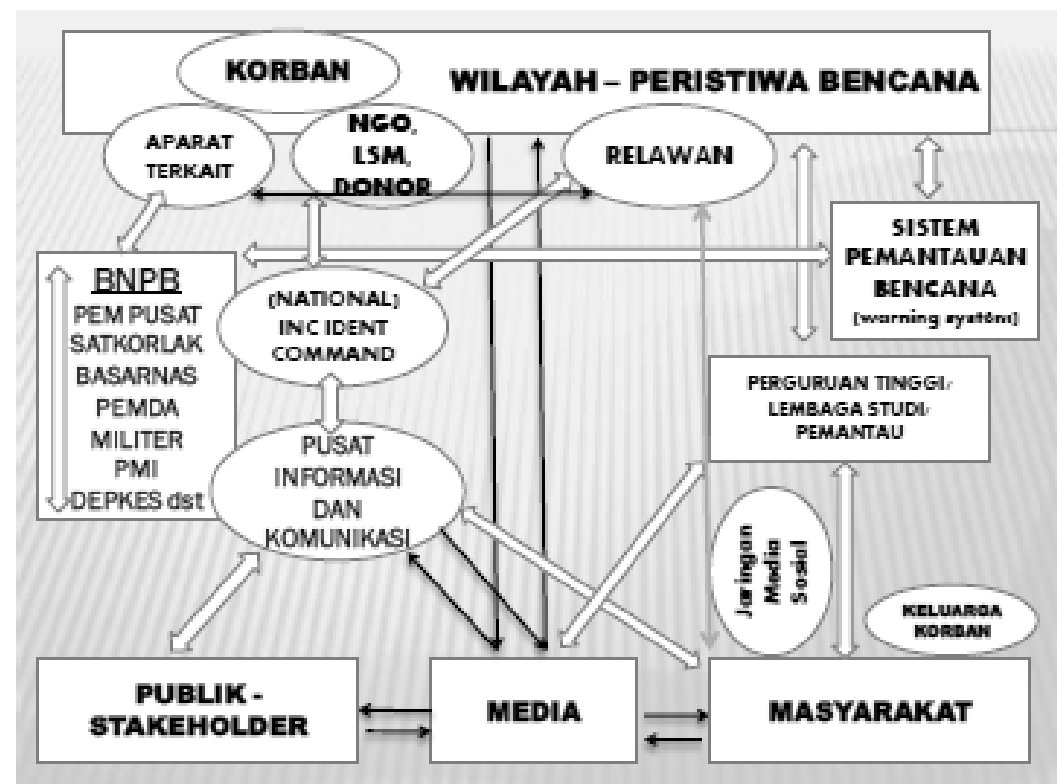

Setio Budi HH (2011 : 33)

Bagan 3

Keterlibatan Stakeholder Dalam Peristiwa Bencana 
Bagan diatas menunjukkan kompleksitas organisasi, manajemen dan operasi penanggulangan bencana, terutama antara pihak yang menjadi ujung tombak dan berbagai lembaga atau perorangan yang dianggap/ menganggap memiliki kapasitas untuk melakukan asistensi pada suatu peristiwa bencana. Bagan tersebut awalnya dibuat sebagai resume atas peristiwa bencana letusan gunung Merapi tahun 2010. Pertama, peristiwa letusan tersebut sebelumnya telah dipantau, diketahui/ diperkirakan akan terjadi dan sampai akhinya terjadi. Kedua peristiwa letusan Merapi yang telah dikatagorikan sebagai bencana nasional tersebut terjadi pada kurun waktu yang cukup panjang (Oktober Desember tahun 2010), dari skala kecil sampai pada puncak letusan, termasuk pasca letusan, yaitu gelontoran aliran lahar dingin (pasca puncak letusan Merapi adalah situasi musim hujan).
Dalam pengamatan baik dari media, monitoring frekuensi RAPI dan kisahkisah yang dikemukakan oleh relawan, menunjukkan perbaikan manajemen bencana di Yogya, pasca bencana gempa Yogya tahun 2006 yang lalu, walaupun juga tetap masih menyisakan berbagai persoalan, yang salah satu intinya adalah "KIKK" sebagaimana tersebut diatas. Sebagaimana pada bagan 2 diatas garis-garis koordinasi/ fungsi dan berbagai komponen/stakeholder yang ada, pada suatu peristiwa bencana adalah mencakup muatan-muatan dan probelematika "Komunikasi, Informasi, Koordinasi dan Kerjasama".

\section{Siklus Manajemen Bencana}

Pada dasarnya pemahaman manajemen bencana akan mencakup aspek sebagaimana yang dikemukakan Shaw dan Gupta (dalam Shaw, Srinivas, Sharma, 2009 : 57) dibawah ini :

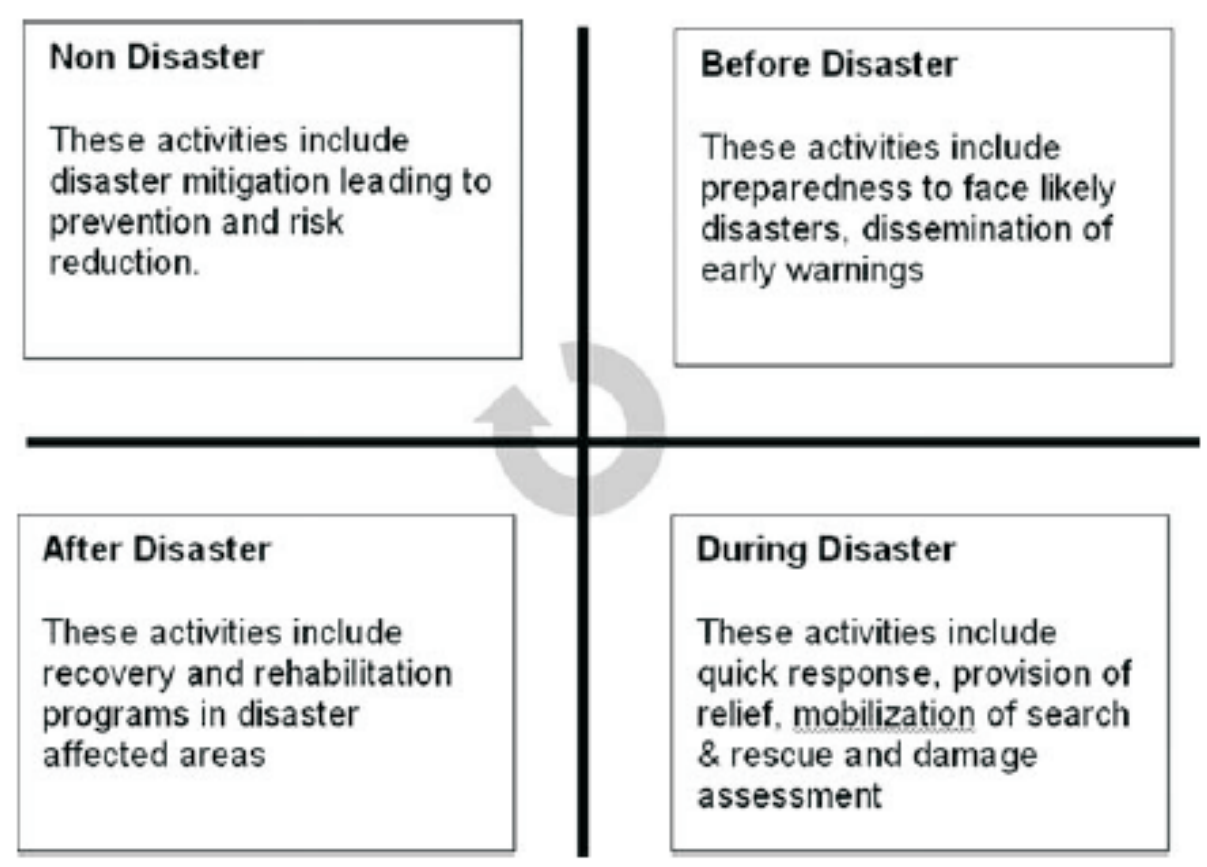

Bagan 4.a

Siklus Manajemen bencana 
Secara siklus akan mencakup situasi sebelum bencana, selama bencana, setelah peristiwa bencana dan situasi non bencana. Pada situasi non bencana adalah gambaran mengenai proses mitigasi.
Pada paparan berikut Shaw dan Gupta (2009 : 59) secara khusus menyoroti isu komunikasi dalam manajemen bencana, sebagai mana bagan berikut ini :

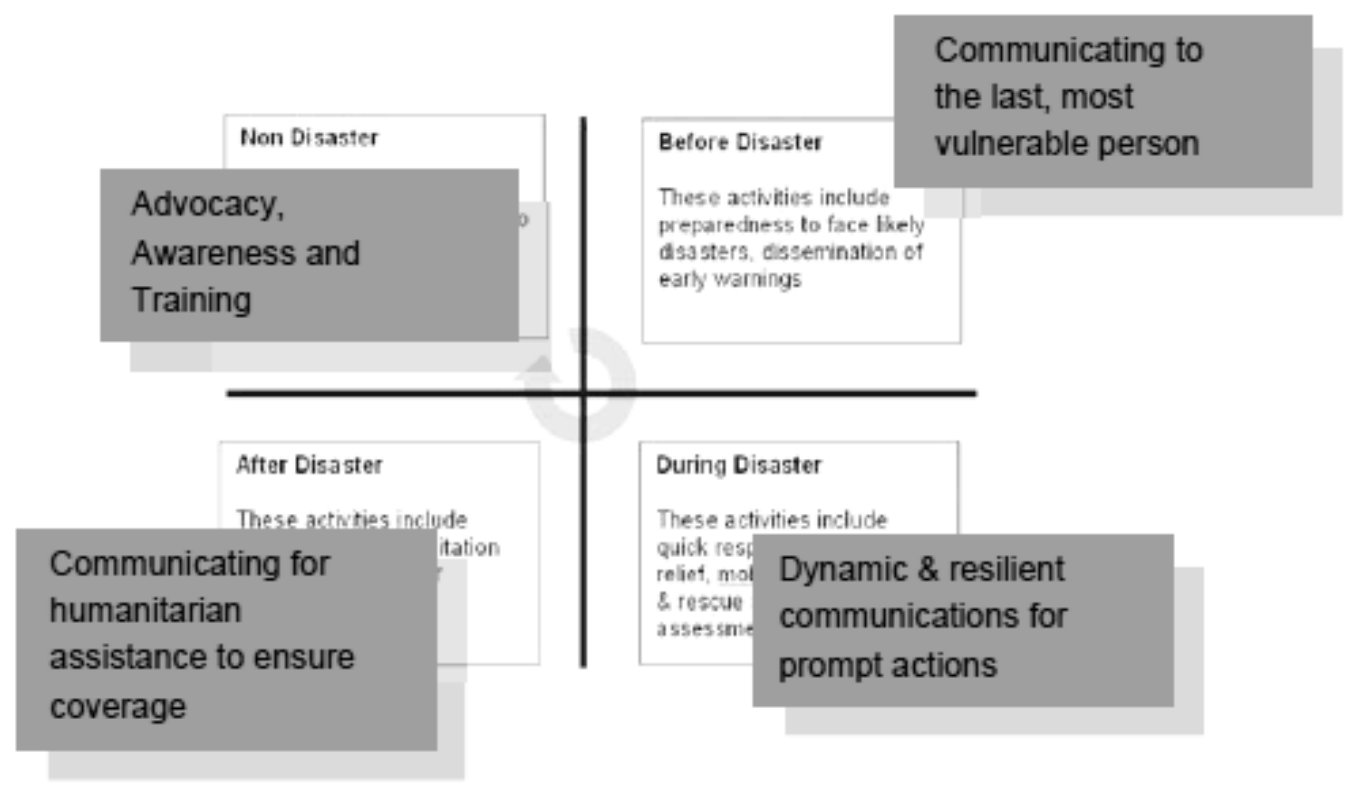

Bagan 4.b

Isu Komunikasi Dalam Manajemen Bencana

Memang Shaw dan Gupta fokus menyoroti aspek komunikasi, namun sebenarnya ada implikasi lebih ketika kita menghubungkan antara siklus manajemen komunikasi dan aspek komunikasi, yaitu dimensi informasi, koordinasi dan kerjasama. Pada tahap sebelum kejadian bencana maka aspek komunikasi akan mencakup informasi yang akurat, koordinasi dan aspek kerjasama terutama kepada masyarakat yang rentan atas peristiwa bencana. Pada tahap kejadian bencana keempat aspek : komunikasi, informasi, kerjasama dan koordinasi merupakan kunci sukses penangana bencana, terutama untuk penanganan korban dan menghindari resiko lebih lanjut. Pada tahap setelah bencana rekonstruksi dan pemulihan pasca situasi bencana adalah tahap penting untuk membangun kembali korban bencana dan memastikan untuk mengurangi resiko apabila terjadi peristiwa serupa dikemudian hari. Dan yang sangat penting adalah mitigasi, dalam tahapan ini, seluruh potensi komunikasi menjadi penting untuk memastikan pencegahan dan pengurangan resiko, yang tentu pendekatan yang tepat adalah konprehensif, sistemik dan terintegrasi antar lembaga, komponen maupun stakeholder yang ada.

Secara lebih luas, selain lembaga yang menangani bencana (BNPB), keterlibatan stakeholder seperti media, industri, politisi dan berbagai komponen masyarakat/ lembaganya menjadi sangat penting. Sedemikan penting agar keterlibatan mereka terutama pada peristiwa bencana dan juga pada mitigasi, 
tahap pemulihan, tidak digunakan sebagai ajang pencitraan - yang akhirnya menjadikan bencana dan korban bencana sebagai obyek semata, namun justru secara substansial memang membantu korban bencana dan meminimalisasi resiko yang ada/ yang akan terjadi. Pada sisi lain pemberitaan di media atas bencana letusan gunung Merapi, juga sempat menunjukkan adanya tumpukan bantuan yang mubazir, karena tumpang tindih dan system informasi yang tidak baik, atau sebaliknya kejadian bencana gempa di Mentawai dan banjir di Wasior Papua, juga menunjukkan gambaran aspek komunikasi dan informasi yang belum bnerjalan dengan baik karena mengakibatkan keterlambatan penanganan, termasuk bantuan pada korban.

Rodrigues dkk (dalam Rodr'iguez, Quarantelli and Dynes (2007 :480) menyusun model untuk mengkomunikasikan resiko bahaya dan peringatan bencana, sebagai berikut :

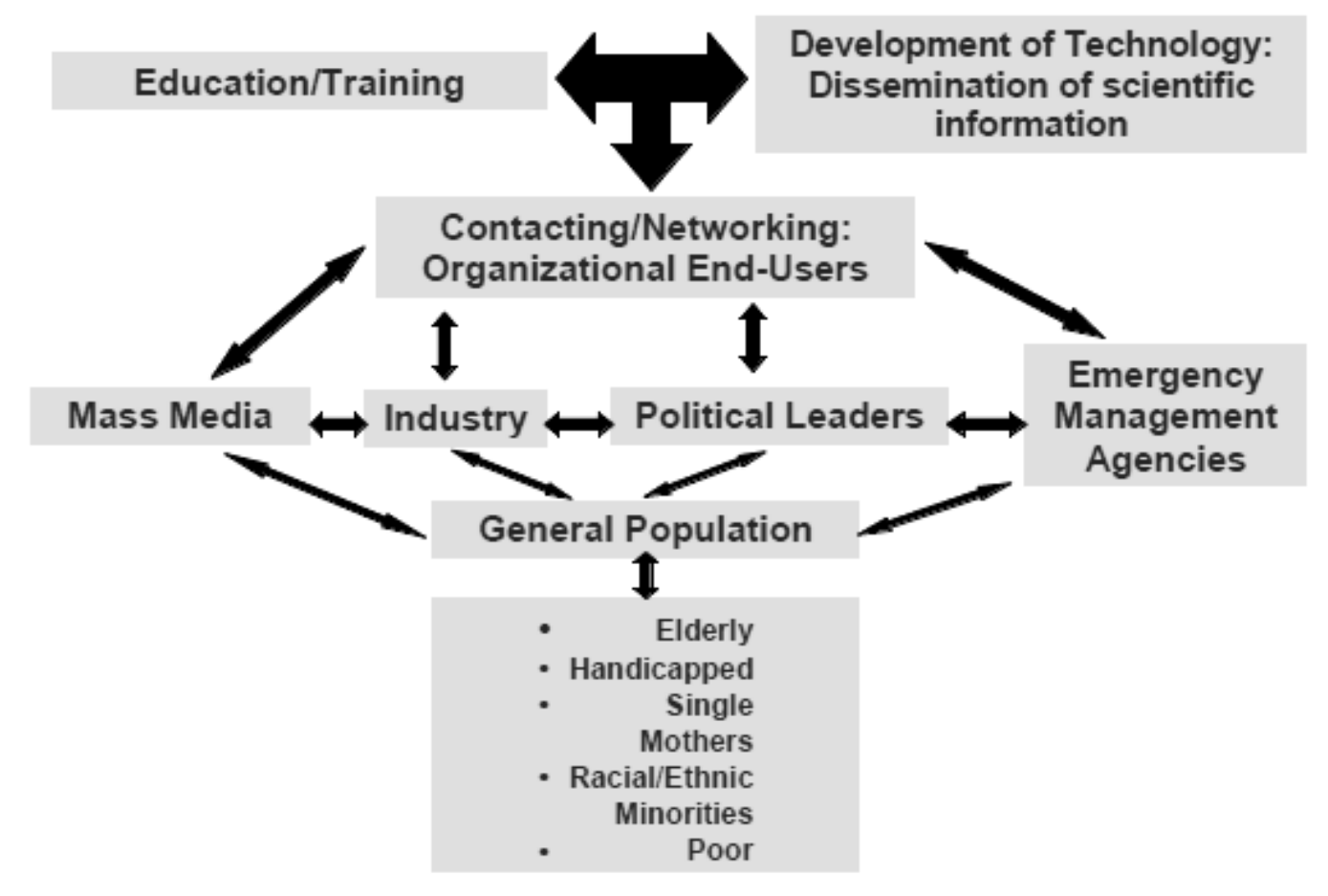

Bagan 5

Model Komunikasi Resiko Bahaya dan Peringatan Bencana

Dari bagan diatas dapat ditarik garis penting bahwa model komunikasi yang dipaparkan tidak hanya memiliki implikasi satu arah antara penggagas dengan targek khalayak yaitu korban/ potensi korban, namunjuga menunjukkan arti penting komunikasi dua arah. Pada sisi lain stakeholder yang terlibat memiliki potensi sumber daya yang bisa digunakan untuk memastikan proses manajemen bencana dan tahapannya bisa mencapai sasaran, oleh karena itu aspek koordinasi dan kerjasama perlu dikembangkan menjadi suatu proses yang baik dengan dasar prinsip humanitarian. Inilah yang sebenarnya menjadi hal penting dalam 
pendekatan system, yaitu integrasi proses antar komponen dan antar stakeholder dalam melakukan gerakan dan tindakan untuk menyelamatkan korban dan potensi korban bencana.

Senada dengan hal tersebut Haddow and Haddow (2009) menyebutkan tentang pentingnya fokus pada target khalayak, artinya memahami karateristik khalayak untuk memastikan pesan dan media untuk isu kebencanaan bisa mendorong ke tindakan dan perilaku mitigasi bencana. Demikian pula aspek komitmen kepemimpinan dari lembaga-lembaga yang relevan dalam penanggulangan bencana, supaya tidak terjadi tumpang tindih, kekacauan koordinasi dan keengganan kerjasama (karena budaya organisasi, pemahaman tentang bencana yang berbeda ataupun jobdes yang berbeda). Selanjutnya adalah isu perencanaan dan operasi komunikasi yang terbuka, apa yang dimaksud terbuka adalah masing-masing pihak paham akan posisi dan tujuan komunikasi yang dilakukan. Jika kondisi ini tidak terjadi akan menimbulkan prasangka atau resistensi dari korban bencana karena kecurigaan adanya kepentingan tertentu yang bermain. Ini tentu termasuk edukasi tentang kebencanaan - kewilayahan dan resiko-resiko, agar khalayak tahu dan paham akan situasi yang terjadi saat ini dan kedepan. Pada isu lain Haddow dan Haddow juga menyoroti media, yang memiliki peran penting dalam peristiwa bencana, dalam arti positif bisa mengedukasi masyarakat dan membantu mengurangi resiko dan membangun spirit korban, sebaliknya tidak menjadikan bencana sebagai komoditas berita semata.

Ross Prizzia (dalam Pinkowski , 2008 : 80-81) menyebutkan pelajaran penting tentang manajemen bencana pada peristiwa Badai Katrina, yaitu dibalik besarnya dan dampak bencana, aspek pemimpin situasi darurat yang tidak cukup memiliki bekal training sebelumnya, tidak cukup memiliki kapasitas untuk menangani peristiwa bencana tersebut, termasik aspek manajemen keuangannya, sebelum, selama dan pasca bencana Katrina tersebut. Prizzia (hal 93 - 94) menambahkan mengenai lemahnya koordinasi dengan sektor swasta/ perusahaan dan juga media, yang pada dasarnya menjadi partner penting dalam manajemen bencana.

\section{Penutup}

Berbagai peristiwa bencana di dunia dan terutama di Indonesia terlihat semakin menunjukkan jumlah dan dampak yang membesar. Proses manajemen bencana diperlukan untuk melakukan pengurangan resiko bencana, untuk hal ini, pemahaman mengenai siklus dan pendekatan manajemen bencana.

Pada akhirnya peristiwa bencana dan aspek menajemen bencana adalah operasi humanitarian, oleh karena itu faktor-faktor determinan yang penting perlu untuk dikembangkan, dilatih dan diaplikasikan. Faktor-faktor yang sering menjadi persoalan adalah Komunikasi, Informasi, Koordinasi dan Kerjasama.

Terutama jika melibatkan berbagai lembaga/ komponen masyarakat, pendekatan yang perlu diketahui, dipahami dan diimplementasikan dengan prinsip humanitarian adalah pendekatan system, yang merupakan upaya sinergis dan terintegrasi dari lembaga yang ditugaskan untuk menangani bencana dan lembaga pendukung lainnya, sedemikian menjadi satu teamwork yang kuat melaksanakan upaya pengurangan resiki bencana. 
Pendekatan system menjadi kunci penting dalam manajemen bencana, dan aspek komunikasi bencana menjadi hal yang juga signifikan, terutama untuk aspek edukasi, komunikasi.informasi selama peristiwa bencana dan pemulihan bencana.

\section{Daftar Pustaka}

Budi HH, Setio (ed), 2011, Komunikasi Bencana, Penerbit : ASPIKOM, PERHUMAS Yogyakarta dan Buku Litera

Coppola, Damon, Maloney, Erin K, 2009, Emergency Preparedness Strategies for Creating a Disaster Resilient Public. Taylor and Francis Group, LLC

Haddow , George D. and Haddow , Kim S. 2009, Disaster Communicationsin a Changing Media World, Elsevier Inc Burlington, MA 01803, USA

Miller , DeMond Shondell \& Rivera, Jason David (eds), 2011, Comparative emergency management : examining global and regional responses to disasters, Taylor and Francis Group, LLC Florida

Pinkowski, Jack (ed), 2008, Disaster Management Handbook, Taylor \& Francis Group, LLC

Rodr'iguez , Havid'an, Quarantelli , Enrico L., and Dynes, Russell (eds), 2007 Handbook of Disaster Research. Springer Science+Business Media, LLC New York

Shaw , Rajib; Srinivas, Hari \& Sharma, Anshu (Eds), 2009, Urban Risk Reduction: An Asian Perspective, Emerald Group Publishing Limited Simonovi'c, Slobodan P, 2011, Systems Approach to Management of Disasters : Methods and Applications, John Wiley \& Sons Hoboken, New Jersey

Paper

Budi HH, Setio"Mitigasi dan Manajemen Komunikasi Bencana" Dipresentasikan dalam Seminar \& Call for Paper The Power of Green: Media dan Komunikasi Lingkungan", MILAD UNISBA 2011 